\title{
Association of SIRT-1, T helper 17-associated gene and Antimicrobial Peptides Genes in Inflammatory Bowel Disease Patients
}

\author{
Magdy Amin El Serafy ${ }^{1}$, Dina Sabry ${ }^{1}$, Mohammed Ahmed Mohey El din ${ }^{1}$, Ahmed \\ Moustafa $^{1}$, Amany El Kazaz ${ }^{2}$, Shereen Rashad Mohammed ${ }^{3}$, Amany A Abou-Elalla ${ }^{4}$ \\ ${ }^{I}$ Cairo University, Cairo, Egypt \\ ${ }^{2}$ Suez Canal University, Ismailia, Egypt \\ ${ }^{3}$ Fayoum University, Al Fayoum, Egypt \\ ${ }^{4}$ Misr University for Science and Technology, Giza, Egypt
}

\begin{abstract}
The aim of this study was to assess the expression of Th17-associated gene, genes encoding antimicrobial peptides (AMPs) and SIRT-1 protein in patients with inflammatory bowel disease (IBD).

Patients and Methods: We studied a group of 20 IBD patients, together with 20 subjects served as controls. Colonoscopy, terminal ileoscopy, and colonoscopic biopsy were performed for histopathology diagnosis, and quantitative gene expression of Th17-associated gene, CAMP, Elafin and SLPI by real-time PCR. SIRT-1 protein level expression was assessed by western blot.

Results: The expression of the four studied genes - elafin, SLPI, CAMP and Th17-associated gene - by relative quantification was higher in the patient group than in the control group. A statistically significant positive correlation was found between SLPI and elafin in the patient group $(r=0.8325, P<0.001)$. A statistically significant positive correlation was reported as well between CAMP levels and elafin levels in the patient group $(r=0.6842, P<0.001)$. In addition, CAMP levels had a positive correlation with SLPI levels in the patient group $(r=0.6373, P<0.001)$. The highest expression of SIRT-1 was found in severe cases of IBD and the lowest expression was demonstrated in control subjects. A statistically significant positive correlation was detected between IL-17 levels and SIRT-1 levels in the patient group $(r=0.7822, P<0.001)$.

Conclusion: A high expression of Th17-associated gene and AMPs gene has a significant impact on clinical assessment of patients with IBD. SIRT may participate in the progression of IBD. (International Journal of Biomedicine. 2017;7(3):196-203.)
\end{abstract}

Key Words: Th17-associated gene $\bullet$ inflammatory bowel disease $\bullet$ antimicrobial peptides $\bullet$ elafin $\bullet$ SIRT-1

\section{Abbreviations}

AMPs, antimicrobial peptides; CD, Crohn's disease; CAMP, cathelicidin antimicrobial peptide; DEFB1, defensin beta 1; GWAS, genome-wide association studies; IBD, inflammatory bowel disease; LEAP2, liver expressed antimicrobial protein 2; SLPI, secretory leucocyte peptidase inhibitor; SIRT-1, silent information regulator-1; Th, T helper; UC, ulcerative colitis.

\section{Introduction}

The term inflammatory bowel disease (IBD) mainly covers ulcerative colitis (UC) and Crohn's disease (CD). IBD is a global health problem, with a reported prevalence as high as 568 and 827 per 100,000 in the USA and Europe, respectively. ${ }^{(1)}$

*Corresponding author: Dina Sabry Abd El Fatah, Professor of Medical Biochemistry and Molecular Biology of the Cairo University,Egypt.E-mail: dinasabry@kasralainy.edu.eg
CD can manifest itself anywhere in the gastrointestinal tract, while UC is only seen in the colon, with a varying length and degree of continuous inflammation extending proximally from the rectum. In UC, the inflammation is found in the mucosa while in $\mathrm{CD}$, there is a deeper, often transmural inflammation with formation of strictures and fistula. Among complex diseases, GWAS have been successful in IBD, identifying 99 non-overlapping genetic risk loci, including 28 that are shared between CD and UC. ${ }^{(2,3)}$ GWAS have generated insights into the mechanisms driving IBD and have implicated 
genes shared by multiple autoimmune and autoinflammatory diseases. Nevertheless, the challenge remains to determine how genetic variation can precipitate and sustain the inappropriate inflammatory response to commensals that is observed in IBD. ${ }^{(4)}$ The coordinated effect of various Th subtypes is fundamental to gut homeostasis, ${ }^{(5)}$ and $\mathrm{UC}$ and $\mathrm{CD}$ have been considered different with respect to Th cell activation. ${ }^{(6)}$ The concept of Th17 cells has been introduced, and it was shown that inflammation previously attributed to Th1 could actually be Th17-driven and that these lymphocytes played an important role in $\mathrm{CD} .{ }^{(7,8)}$ The identification of Th17 as a unique subset of Th cells has challenged this view, and today some argue that the adaptive immune response in $\mathrm{CD}$, and to some degree in UC, is dominated by Th1/Th17 cells. (9) Antimicrobial peptides (AMPs) have been identified as essential peptides in the maintenance of intestinal barrier function and immune homeostasis. Human peptides detectable in the gastrointestinal tract are divided into $\alpha$ - and $\beta$-defensins (HD and HBD, respectively) and the cathelicidin LL-37, based on their amino-acid sequences. ${ }^{(10)}$ There is increased expression of many AMPs in both inflamed $\mathrm{UC}$ and $\mathrm{CD}$ mucosa, with only a few interesting exceptions. DEFB1 is significantly down-regulated in both $\mathrm{UC}$ and $\mathrm{CD}$, while the gene encoding LEAP2 showed a similar, but less prominent regulation. The loss of DEFB1 expression has previously been reported by Arijs et al., who suggested that alterations may be due to a loss of epithelial tissue in the inflamed colon. ${ }^{(1)} \mathrm{A}$ work by Peyrin-Biroulet et al. describes the role of DEFB1 in maintaining homeostasis, and explores the regulation of colonic DEFB1 expression. ${ }^{(12)}$ In IBD, leukocyte infiltration, Paneth cell metaplasia, crypt hyperplasia and ulceration with loss of epithelial cells are factors that will influence measured levels of gene expression. As an example, the increase in $\alpha$-defensin expression in colonic IBD has been attributed to colonic Paneth cell metaplasia, while the decrease of $\alpha$-defensin expression in ileal CD has been linked to the loss of epithelial tissue, Paneth cell function and NOD2 status. ${ }^{(13-15)}$ Another effect potentially interfering with IBD microarray analysis is the regional variation in gene expression, with both a dichotomous and a more gradually varying gene expression pattern along the colon. ${ }^{(16)}$ Recently, numerous studies have demonstrated the impact of the NAD-dependent deacetylase sirtuin-1 (Sirt1) on human aging, age-related diseases, genome stability and inflammatory response. ${ }^{(17,18)} \mathrm{We}$ investigated the expression of Th17-associated gene and AMPs gene and evaluated their impact on clinical presentation of Egyptian patients with IBD. We also aimed to assess the expression level of SIRT-1 protein and its role in disease propagation.

\section{Patients and Methods}

This is a case control, cross-sectional study that was conducted on 40 adult subjects referred to the Gastrointestinal Endoscopy and Liver Unit, Cairo University. Half of the patients had IBD, the other half were non-IBD subjects studied as case control. The study protocol was reviewed and approved by the Ethics Committee of the Cairo University Faculty of Medicine and Department of Endemic medicine.
All participants provided the written informed consent. The twenty IBD patients were selected out of a total of 80 patients who presented to our endoscopy unit from July 2013 to January 2015. The remaining 60 patients were excluded because they did not fit with our inclusion criteria (age, denial of consent, disagreement between endoscopic and histopathologic findings, dropout). The selection criteria included: (a) adult patients 18 years or older from both sexes who are willing to participate and to give an informed consent; (b) patients within the clinical spectrum consistent with IBD that was confirmed both endoscopically and histopathologically. The exclusion criteria included: (a) patients who have a discrepancy between endoscopic and histological assessments, making it difficult to establish and confirm a diagnosis of UC or CD; (b) patients who have an indeterminate colitis by histopathology.

All enrolled subjects were subjected to full history taking, stressing symptoms related to IBD, such as chronic diarrhea, weight loss, joint manifestations or other autoimmune associations. Subjects were given a full clinical examination, and we assessed and analyzed body mass index (BMI), complete blood count, CRP by ELISA, qualitative fecal calprotectin by ELISA and stool culture for Shigella on MacConkey agar supplemented with xylose and for E-coli on MacConkey agar containing sorbitol. Colonoscopy, terminal ileoscopy, and colonoscopic biopsy were performed for histopathology diagnosis, and quantitative gene expression of Th17-associated gene, CAMP, Elafin and SLPI by real-time PCR. SIRT-1 protein level expression was assessed by western blot.

\section{Real Time PCR}

Colonic mucosal tissues of both studied groups were homogenized and RNA was extracted with an RNAeasy Mini Kit (Qiagen). Out of the total RNA from each sample, $1000 \mathrm{ng}$ was used for PCR amplification using ViPrime One step RTqPCR 2X SyberGreen Mix, HRoxin a 48-well plate using the Step One instrument (Applied Biosystem, USA) as follows: 15 minutes at $50^{\circ} \mathrm{C}$ for cDNA synthesis, 10 minutes at $95^{\circ} \mathrm{C}$ for enzyme activation followed by 40 cycles of 15 seconds at $95^{\circ} \mathrm{C}, 20$ seconds at $55^{\circ} \mathrm{C}$ and 30 second at $72^{\circ} \mathrm{C}$ for the amplification step.. Changes in the expression of each target gene were normalized relative to the mean critical threshold (CT) values of GAPDH as a housekeeping gene by the $\Delta \Delta \mathrm{Ct}$ method. We used $1 \mu \mathrm{M}$ of both primers specific for each target gene. Primers sequence specific for each gene demonstrated in Table (1).

Table 1.

Primers sequence specific for each gene

\begin{tabular}{|l|l|l|}
\hline $\begin{array}{c}\text { Target } \\
\text { gene }\end{array}$ & \multicolumn{1}{|c|}{ Primer sequence: ` $^{\prime}$ 3` } & \multicolumn{1}{c|}{$\begin{array}{c}\text { Gene bank } \\
\text { accession number }\end{array}$} \\
\hline IL-17A & $\begin{array}{l}\text { F: CTGTCCCCATCCAGCAAGAG } \\
\text { R: AGGCCACATGGTGGACAATC }\end{array}$ & NG_033021.1 \\
\hline CAMP & $\begin{array}{l}\text { F:TGCCCAGGTCCTCAGCTAC } \\
\text { R:GTGACTGCTGTGTCGTCCT }\end{array}$ & NM_004345.4 \\
\hline Elafin & $\begin{array}{l}\text { F:CGTGGTGGTGTTCCTCATC } \\
\text { R:TTCAAGCAGCGGTTAGGG }\end{array}$ & S78387.1 \\
\hline SLPI & $\begin{array}{l}\text { F: CCTGCCTTCACCATGAAGT } \\
\text { R:CCAAATGTCAGGAATCAGAC }\end{array}$ & NG_028137.1 \\
\hline GAPDH & $\begin{array}{l}\text { F:CTCTACTGGCGCTGCCAAGGCT } \\
\text { R: GTCCACCACTGCACGTTGG }\end{array}$ & NT_009759.16 \\
\hline
\end{tabular}




\section{Western blotting}

The antibody used was antigen affinity-purified polyclonal sheep IgG anti-human SIRT1 (R\&D Systems, Cat N0: AF7714). Colonic mucosal tissue was subjected to a protein extraction procedure using ReadyPrep ${ }^{\mathrm{TM}}$ protein extraction kit (BIO-RAD, Catalog \#163-2086). Protein was separated by SDS-PAGE on 4\%-20\% polyacrylamide gradient gels. After incubation in 5\% non-fat dry milk, Tris-HCL, $0.1 \%$ Tween 20 for $1 \mathrm{hr}$, the SIRT1 polyclonal monoclonal antibody was added to one of the membranes containing specimen samples and incubated at $4^{\circ} \mathrm{C}$ overnight. Appropriate secondary antibodies were incubated for $2 \mathrm{hr}$ at room temperature. After the antibodies were washed twice in 1xTBS-T, we performed densitometric analysis of the immunoblots to quantify the amounts of SIRT1 against a control sample by total protein normalization by image analysis software on the ChemiDoc MP imaging system (version 3) produced by Bio-Rad (Hercules, CA).

The statistical analysis was performed using SAS 9.2 for windows 7. Baseline characteristics were summarized as frequencies and percentages for categorical variables and as mean $\pm \mathrm{SD}$ for continuous variables. Student's unpaired and paired t-tests were used to compare two groups for data with normal distribution. Differences of continuous variables departing from the normal distribution were tested by the Mann-Whitney U-test. Group comparisons with respect to categorical variables are performed using chi-square tests or, alternatively, Fisher's exact test when expected cell counts were less than 5. Prediction model was performed for calculating predicted probabilities. A probability value of $P<0.05$ was considered statistically significant.

\section{Results}

A total of 40 study patients and controls who underwent complete colonoscopic examination and who complained of abdominal pain, bleeding, diarrhea and constipation were enrolled in this study. Demographic data of all subjects are shown in Table 2. There was no statistically significant difference in either age or sex distribution between the two groups. The control group showed a statistically significant higher mean BMI than did the patient group $(P=0.001)$. The assessment of clinical manifestations in the patient group revealed that all patients complained of diarrhea, $60 \%$ had 6 or more motions per day, and of that $60 \%, 8$ patients complained of passage of blood in stools. While $75 \%$ of the control group complained of diarrhea, all of them had fewer than 6 motions per day and none of them complained of passing blood in stools.

Table 2.

Demographic data of both studied groups

\begin{tabular}{|l|c|c|c|}
\hline \multicolumn{1}{|c|}{ Variable } & Patient group & Control group & $P$ \\
\hline Age (years) & $33.8 \pm 9.88$ & $37.05 \pm 9.04$ & 0.28 \\
\hline Sex(males/females) & $16 / 4$ & $11 / 9$ & 0.17 \\
\hline BMI & $25.0 \pm 3.3245$ & $29.15 \pm 3.065$ & 0.001 \\
\hline
\end{tabular}

All patients complained of abdominal cramps, while only $18(90 \%)$ of the control group experienced this complaint. All patients and half of the control group complained of easy fatigability. Hip joint pain was reported in $80 \%$ of the patient group while it was present only in $2(10 \%)$ cases of the control group. Assessment of the distribution of joint pain showed that $87.5 \%$ of the patient group who experienced joint pain complained of pain in two or more big joints, while only 2 cases in the control group experienced pain in only the hip joint (Table 3).

Table 3.

\section{Clinical features of both studied groups}

\begin{tabular}{|l|c|c|}
\hline \multicolumn{1}{|c|}{ Clinical parameter } & Patient group & Control group \\
\hline Diarrhea & $20(100 \%)$ & $15(75 \%)$ \\
\hline $\begin{array}{l}\text { Severity of diarrhea } \\
<6 \text { motions per day (mild to } \\
\text { moderate disease) } \\
6 \begin{array}{l}\text { or more motions per day } \\
\text { severe disease) }\end{array}\end{array}$ & $8(40 \%)$ & $15(75 \%)$ \\
\cline { 2 - 3 } Blood in stool & $8(40 \%)$ & 0 \\
\hline Constipation & 0 & $3(15 \%)$ \\
\hline Abdominal cramps & $20(100 \%)$ & $18(90 \%)$ \\
\hline Easy fatiguability & $20(100 \%)$ & $10(50 \%)$ \\
\hline Joint pain & $16(80 \%)$ & $2(10 \%)$ \\
\hline $\begin{array}{l}\text { Extent of arthralgia } \\
\text { Single joint } \\
2 \text { or more joints }\end{array}$ & $2(12.5 \%)$ & $2(100 \%)$ \\
\cline { 2 - 3 } & $14(87.5 \%)$ & 0 \\
\hline
\end{tabular}

All the study group cases were negative for ova and parasites by stool analysis or Shigella and E coli by stool culture. Fecal calprotectin was tested and it was positive in $70 \%$ of the study group and negative in the control group.

Both TLC and CRP were significantly higher in the patient group compared to the control group (Table 4). The colonoscopic findings and histopathological results of the patient group showed that 18 cases were diagnosed as UC and 2 cases were diagnosed as CD (Table 5).

Table 4.

Blood tests in both studied groups

\begin{tabular}{|l|c|c|c|}
\hline \multicolumn{1}{|c|}{ Variable } & Patient group & Control group & $P$ \\
\hline $\mathrm{Hb}(\mathrm{g} / \mathrm{dL})$ & $10.95 \pm 1.328$ & $11.61 \pm 1.8$ & 0.19 \\
\hline $\mathrm{TLC}\left(\times 10^{3} / \mathrm{cmm}\right)$ & $13.85 \pm 1.56$ & $6.01 \pm 1.12$ & $<0.001$ \\
\hline $\mathrm{CRP}(\mathrm{mg} / \mathrm{L})$ & $51.9 \pm 9.60$ & $6.7 \pm 1.94$ & $<0.001$ \\
\hline
\end{tabular}

The expression of the four studied genes - elafin, SLPI, CAMP and Th17-associated gene-by relative quantification was higher in the patient group than in the control group (Table 6). In patients with severe disease, the levels of elafin, CAMP and SLPI were higher than those in patients with mild to moderate disease, and this difference is statistically significant $(P<0.001$ in all cases). No statistically significant difference was detected between two groups of patients regarding the IL17 level (Table 7, Fig. 1). 
Table 5.

Colonoscopic findings and histopathological results of the cases

\begin{tabular}{|l|c|}
\hline Colonoscopic findings & Patients \\
\hline UC & $15(75 \%)$ \\
Erythema and erosions in rectum (proctitis) & $14(70 \%)$ \\
Erythema and erosions up to the splenic flexure & \\
(left sided colitis) & $18(90 \%)$ \\
Loss of the fine vascular pattern & $10(50 \%)$ \\
Pseudopolyps & $15(75 \%)$ \\
Ulcers & \\
\hline CD & \\
Serpiginous ulcers with cobblestone appearance in & $1(5 \%)$ \\
left colon & $1(5 \%)$ \\
Small discrete aphthous ulcers with normal adjacent \\
mucosa in left colon & \\
\hline Histological findings & \\
\hline UC & $18(90 \%)$ \\
\hline Crypt abscesses & $3(15 \%)$ \\
Crypt branching and shortening & $18(90 \%)$ \\
Basal lymphoid aggregates & $2(10 \%)$ \\
\hline CD & \\
\hline Focal inflammation and granuloma & \\
\hline
\end{tabular}

Table 6.

Mean values of expressed genes in both studied groups

\begin{tabular}{|l|c|c|c|}
\hline Studied genes & Patient group & Control group & $P$ \\
\hline Elafin & $4.157 \pm 0.7$ & $0.95 \pm 0.4$ & $<0.001$ \\
\hline SLPI & $2.917 \pm 0.588$ & $0.476 \pm 0.264$ & $<0.001$ \\
\hline CAMP & $1.63 \pm 0.70$ & $0.018 \pm 0.017$ & $<0.001$ \\
\hline IL 17 & $0.357 \pm 0.26$ & $0.11 \pm 0.04$ & $<0.001$ \\
\hline
\end{tabular}

Table 7.

Association between the studied genes and the disease severity

\begin{tabular}{|l|c|c|c|}
\hline Disease severity & Mild to moderate & Severe & $P$ \\
\hline Elafin & $3.43(0.317)$ & $4.63(0.406)$ & $<0.001$ \\
\hline CAMP & $1.139(0.66)$ & $1.959(0.53)$ & $<0.001$ \\
\hline SLPI & $2.4(0.35)$ & $3.26(0.44)$ & $<0.001$ \\
\hline IL 17 & $0.309(0.21)$ & $0.39(0.29)$ & 0.482 \\
\hline
\end{tabular}

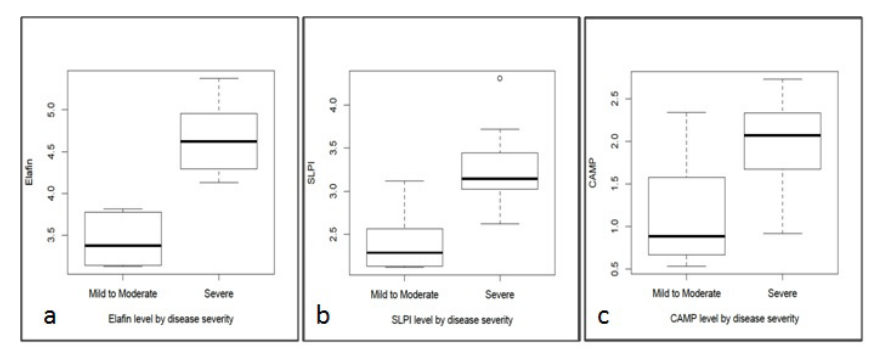

Fig. 1. The association between (a) elafin, (b) SLPI and (c) CAMP levels according to the disease severity in the studied group of patients.
We examined genes of patients in the study group who experienced pain in only one joint and those who experienced pain in two or more big joints, and the results showed higher levels of elafin, CAMP and SLPI in those who experienced pain in two or more big joints, and this difference was statistically significant $(P<0.001$ in all cases $)$. No statistically significant difference in the IL-17 level was detected between the 2 groups of patients (Table 8. Fig. 2). A positive correlation was found between SLPI and elafin in the patient group ( $r=0.8325$ $P<0.001$; Fig. 3). A statistically significant positive correlation was reported as well between CAMP levels and elafin levels in the study group of IBD patients ( $r=0.6842, P<0.001$; Fig..4). In addition, CAMP levels had a positive correlation with SLPI levels in the patient group $(r=0.6373, P<0.001$; Fig. 5$)$. The highest expression of SIRT-1 was found in severe cases of IBD and the lowest expression was demonstrated in control subjects (Fig. 6). A statistically significant positive correlation was detected between IL-17 levels and SIRT-1 levels in the study group of IBD patients $(r=0.7822, P<0.001)$.

\section{Table 8.}

Association between the studied genes and the number of painful joints

\begin{tabular}{|l|c|c|c|}
\hline \multicolumn{1}{|c|}{ Variable } & One joint & 2 or more joints & $P$ \\
\hline Elafin & $3.327(0.28)$ & $4.51(0.48)$ & $<0.001$ \\
\hline CAMP & $0.9282(0.52)$ & $1.93(0.53)$ & $<0.001$ \\
\hline SLPI & $2.32(0.22)$ & $3.173(0.501)$ & $<0.001$ \\
\hline IL 17 & $0.307(0.22)$ & $0.379(0.28)$ & 0.55 \\
\hline
\end{tabular}

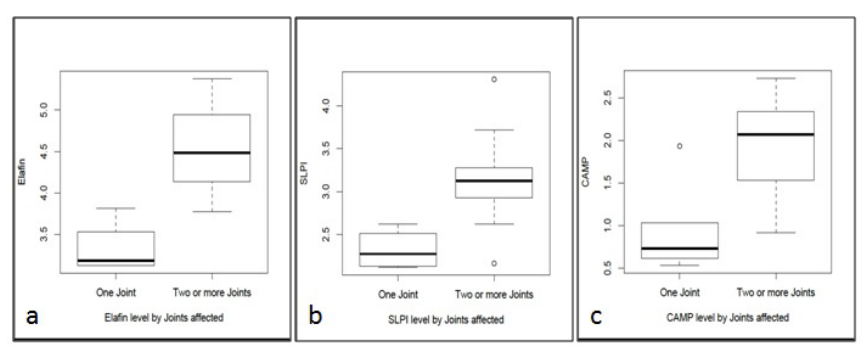

Fig. 2. The association between (a) elafin, (b) SLPI and (c) CAMP levels according to the number of painful joints in the studied group of patients.

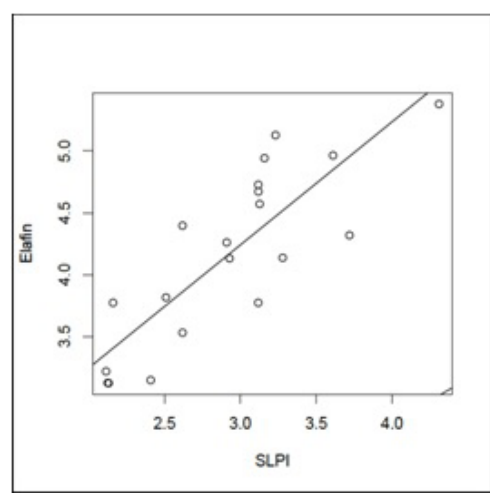

Fig. 3. The correlation between elafin levels and SLPI levels in the studied group of patients. 


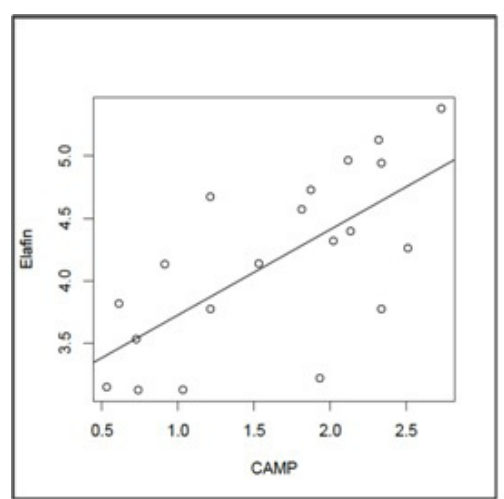

Fig. 4. The correlation between elafin levels and CAMP levels in the studied group of patients.

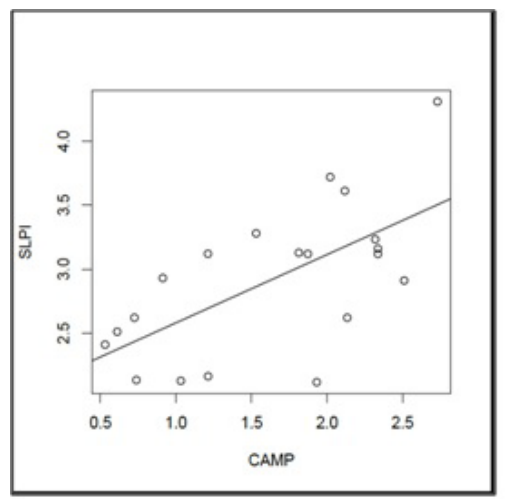

Fig. 5. The correlation between SLPI levels and CAMP levels in the studied group of patients.

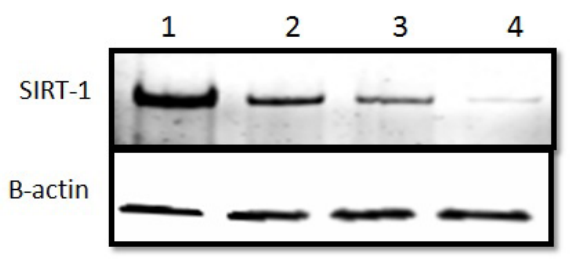

Fig. 6. The scanning densitometry results of SIRT-1 versus $\beta$-actin protein levels in colonic tissues of severe (1), moderate (2), mild (3) IBD and control tissue subjects (4).

Multivariate regression analysis was performed using the studied parameters to predict those with IBD among the 2 groups. Results revealed that age, BMI, IL-17 and CAMP can significantly predict the presence of IBD (Table 9).

Table 9.

Multivariate regression analysis

\begin{tabular}{|l|c|c|c|c|}
\hline Variable & Estimate & Std. Error & z- value & $p$-value \\
\hline Intercept & 11.45687 & 7.42840 & 1.542 & 0.1230 \\
\hline IL 17 & 58.70451 & 27.03552 & 2.171 & 0.0299 \\
\hline Age & -0.07364 & 0.07473 & -0.985 & 0.3244 \\
\hline BMI & -0.63515 & 0.30921 & -2.054 & 0.0400 \\
\hline CAMP & 46.56846 & 17.5345 & 1.345 & 0.0189 \\
\hline
\end{tabular}

\section{Discussion}

In our research, we studied a group of 20 patients, together with 20 subjects served as controls; 2 patients in the study group were diagnosed as $\mathrm{CD}$, while 18 were diagnosed as UC. Analysis of the age and sex of the study group showed that the mean age of patients was 33.8 years, with a significant male predominance, which is similar to a finding reported in another study done by Brahmania and Bernstein. ${ }^{(19)}$ Although our results may agree with the known IBD peak in the fourth decade of life and do not agree with the known female predominance, it is important to stress that our patients do not represent a random sample of the general population of IBD patients and that they were included in our study according to specific inclusion criteria.

The diagnosis of IBD in our study was based on standard clinical and endoscopic findings. All patients complained of diarrhea, abdominal cramps, easy fatigability; $60 \%$ of them experienced more than 6 motions per day, $40 \%$ showed blood in stool, $80 \%$ experienced joint pains and $87.5 \%$ of them complained of pain in 2 or more big joints. The mean CRP level was $51.9 \mathrm{mg} / \mathrm{L}$. The mean hemoglobin level was $10.95 \mathrm{~g} / \mathrm{dl}$.

Isene et al. concluded that the cumulative prevalence of first extraintestinal manifestation (mainly arthritis) was $16.9 \%{ }^{(20)}$ Dignasset et al. stated that the main symptom of $\mathrm{UC}$ is visible blood in the stools, which is reported in more than $95 \%$ of active disease. Rectal urgency, tenesmus and occasionally severe constipation represent the classical complaints of rectal involvement, while chronic diarrhea with nocturnal defecation and crampy abdominal pain are typical of left-sided or extensive UC.(21)

Lennard-Jones and Shivananda concluded that patients affected by Crohn's colitis often present a UC-like clinical phenotype. Blood or mucopurulent exudates with the stool can be seen in up to $40 \%$ to $50 \%$ of patients with Crohn's colitis, but less frequently than in UC subjects. ${ }^{(22)}$ Other studies, by Sands and Van Asscheet, also suggested that chronic diarrhea is the most common presenting symptom in classical ileocolonic $\mathrm{CD}$, followed by abdominal pain and weight loss. ${ }^{(23,24)}$

Consistent with the above clinical features, a nested, case-controlled study by Melmedet et al. showed that UC patients with either non-bloody diarrhea or weight loss as onset symptoms have an increased likelihood of subsequent change in diagnosis to $\mathrm{CD}$, compared to those with none of these risk factors, and might thus warrant further diagnostic work-up. ${ }^{(25)}$ This matches Ricaneket et al., in which more than $50 \%$ of the patients presented with symptoms of abdominal pain, diarrhea, and blood in stool, mainly in those diagnosed as UC; the median CRP level was $26 \mathrm{mg} / \mathrm{L}$ in those diagnosed as $\mathrm{CD}$ and $24 \mathrm{mg} / \mathrm{L}$ in those diagnosed as UC. ${ }^{(26)}$

In our study, colonoscopic examination showed erythema and erosions in the rectum in $90 \%$ of cases and erythema and erosions up to the splenic flexure in $70 \%$ of cases, loss of the fine vascular pattern in $90 \%$ of the cases, pseudopolyps in $50 \%$, and ulcers in $75 \%$; one case showed serpiginous ulcers with cobblestone appearance in the left colon and another one showed small discrete aphthous ulcers with normal adjacent mucosa in the left colon. The histological examination of 
colonic biopsies taken from the patients in our study showed crypt abscesses in $90 \%$ of the cases, crypt branching and shortening in $15 \%$ of the cases, basal lymphoid aggregates in $90 \%$ of the cases, and focal inflammation and granuloma formation in $10 \%$ of the cases. Geboes and De Hertogh stated that one of the main histopathologic differences between $\mathrm{CD}$ and $\mathrm{UC}$ is the microscopic extension of inflammation. In UC, it is localized to the mucosa and submucosa, whereas CD is characterized by a transmural inflammation. As a result, in $\mathrm{CD}$, deep fissuring ulcers may penetrate through the muscle layer, resulting in abscesses or fistulas between involved segments or adjacent organs. ${ }^{(27)}$

Cathelicidins are a family of peptides with established antibacterial, antiviral and antifungal effects. ${ }^{(28)}$ Cathelicidin plays an important role in the pathophysiology of human disease such as Kostmann's syndrome (a severe congenital neutropenia with chronic gingivitis due to the lack of cathelicidin in immature neutrophils). ${ }^{(29)} \mathrm{M}$. Iimura et al. showed that colon epithelial cathelicidin expression is critical for barrier function, bacterial adhesion and surface epithelial cell damage in vivo. ${ }^{(30)}$

In accordance with previous reports, we found that the CAMP mRNA expression was found to be markedly elevated in patients in the study group compared to controls $(P=0.00)$. CAMP expression was significantly higher in patients with severe disease. The same results were found when we studied the association with joint pain; significantly higher expression of CAMP was found in those who experienced pain in 2 or more big joints $(P<0.001)$. This increase in CAMP levels may be due to the inflammatory nature and the breakdown of the colon epithelial barrier in IBD. AMPs, like cathelicidins, are located at epithelial surfaces.

Schauberet et al. found that cathelicidin expression was significantly increased in inflamed colon mucosa from UC patients compared to non-inflamed mucosa in the controls. ${ }^{(31)}$

During colitis, a delicate equilibrium is established between proteases and antiprotease. ${ }^{(32)}$ In inflammatory states, proteases injure tissues while protease inhibitors stabilize tissue damage and facilitate healing. Elafin and SLPI are protease inhibitors that modulate inflammation via its anti-protease activity. ${ }^{(33)}$ In UC patients, elafin and SLPI levels are high and may tend to act as a self-protective mechanism against colitis. ${ }^{(34)}$ The systemic concentration of these antiproteases in the serum is comparably low. ${ }^{(35)}$ The main proteolytic activity for elafin and SLPI is directed against human neutrophil elastase, HNE, thus, antagonizing excessive elastase release in the inflamed tissue.

Furthermore, both molecules are capable of antagonizing various other proteases; Elafin inhibits porcine pancreas elastase and proteinase-3, whereas SLPI is also a potent inhibitor of trypsin, chymotrypsin, tryptase, chymase and cathepsin $\mathrm{G} .{ }^{(36-38)}$

In the colon, SLPI and elafin have been found in the normal epithelium, ${ }^{(39,40)}$ and elafin has been shown to be increased in UC. ${ }^{(41)}$ In addition to their function as antiproteases, they are effective antimicrobial peptides, being active against Gram-positive and Gram-negative bacteria, fungi, and viruses..$^{(42,43)}$

In our study, the elafin and SLPI mRNA expression were markedly higher in the study group patients than in the controls $(P<0.001)$. There was an association between the severity of IBD and both elafin and SLPI levels, where both elafin and SLPI mRNA expression were much higher in patients with severe disease $(P<0.001$ for all cases). It was also shown that both elafin and SLPI mRNA expression were much higher in patients who experienced pain in 2 or more big joints $(P<0.001)$.

In our study, there was a positive correlation between elafin and SLPI $(r=0.8325, P<0.001)$. CAMP expression levels were significantly correlated with SLPI levels $(r=0.6373$, $P<0.001)$. A positive correlation was reported as well as between CAMP levels and elafin levels $(r=0.6842, P<0.001)$.

M. Schmid et al. reported that elafin and SLPI correlated with the proinflammatory cytokine IL-8, which has been demonstrated to be a good marker for histological inflammation. They found also that elafin predominated in the epithelium, whereas SLPI was preferentially found in inflammatory cells. ${ }^{(44)}$

Another cell type that recently caught interest in conjunction with IBD is the Th17 cell. This T cell subset produces IL-17A, commonly called IL-17, and IL-17F, which exist as homo and heterodimers and share $60 \%$ amino acid sequence identity. Depending on cell type, IL-17 can therefore trigger expression of many proinflammatory cytokines, including TNF- $\alpha$, IL-1, IL-6, granulocyte colony-stimulating factor, granulocyte-macrophage colony-stimulating factor, and chemokines. ${ }^{(4)}$

In our study, the Th17-associated gene expression was found to be higher in the patient group than in the controls $(P<0.001)$. IL-17 expression levels were slightly higher in patients with severe disease but this difference was not statistically significant.

In accordance with our study, Jiang reported that Th17 cells and Th17-related cytokines (IL-17, IL-21 and IL-22) were significantly increased in the intestinal mucosa of active IBD patients and may play an important role in disease activity and mucosal damage. ${ }^{(46)}$

There were no statistically significant differences in IL17 expression level between those who had pain in 2 or more big joints and those who experienced pain in only one joint $(P=0.55)$.

SIRT-1, a NAD + dependent histone deacetylase, is involved in many pathophysiological processes, such as antiinflammation, metabolism modulation of cell growth and anticarcinogenesis. ${ }^{(47)}$ It regulates inflammation by modulating a variety of pro-inflammatory mediators. ${ }^{(48)}$

A significant increase in TNF- $\alpha$, IL-6, IL-1 $\beta$, IFN- $\gamma$ and IL-17 with suppression in TIMP-3 and SIRT-1 mRNA level was observed during the Dextran Sodium Sulfate (DSS) exposure phase to induce IBD in animals, which reverts to normal towards the remission phase. Treatment with resveratrol, a SIRT-1 activator, significantly elevated SIRT-1 and TIMP-3, suppressed TNF- $\alpha$ converting enzyme (TACE) mRNA expression, and was associated with amelioration of disease. ${ }^{(49)}$

In our study, the levels of SIRT-1 mRNA expression were found to be higher in the patient group compared to controls $(P<0.001)$. SIRT-1 levels were slightly higher in patients with severe disease, but this difference was not statistically significant $(P=0.52)$. Additionally, there was a significant 
positive correlation between IL-17 levels and SIRT-1 levels in patients $(r=0.7822, P<0.001)$. This coincided with a recent study, which reported that Sirt1, when adjusting the pattern of cellular metabolism to nutrient availability, can regulate many metabolic functions including DNA repair, genome stability, inflammatory response, apoptosis, cell cycle, and mitochondrial functions. ${ }^{(18)}$ However, our study disagreed with another study that strongly emphasized the involvement of TACE in colon inflammation and suggested that inhibition of TACE directly or indirectly via SIRT-1 activation ameliorates colitis. ${ }^{(49)}$

Multivariate regression analysis was performed using the studied parameters to predict those with IBD among the studied groups, and our results revealed that age, BMI, IL17 and CAMP can significantly predict the presence of IBD. This agrees with Lukás, who reported that the strongest predictors of disease course in $\mathrm{CD}$ and $\mathrm{UC}$ are the age at diagnosis, disease location and smoking habit. ${ }^{(50)}$

In conclusion, we can apply the biochemical markers IL-17, CAMP, Elafin, SLPI and SIRT-1 for the early diagnosis and treatment intervention of IBD. Our study may reveal a novel pathogenic mechanism linking the NAD-dependent deacetylase Sirt1 and its modulation of IL-17 in IBD.

\section{References}

1. Molodecky NA, Soon IS, Rabi DM, Ghali WA, Ferris M, Chernoff G, et al. Increasing incidence and prevalence of the inflammatory bowel diseases with time, based on systematic review. Gastroenterology. 2012;142(1):46-54 e42. doi: 10.1053/j.gastro.2011.10.001.

2. Franke A, McGovern DP, Barrett JC, Wang K, RadfordSmith GL, Ahmad T, et al. Genome-wide meta-analysis increases to 71 the number of confirmed Crohn's disease susceptibility loci. Nat Genet. 2010;42(12):1118-25. doi: 10.1038/ng.717.

3. Anderson CA, Boucher G, Lees CW, Franke A, D'Amato M, Taylor KD, et al. Meta-analysis identifies 29 additional ulcerative colitis risk loci, increasing the number of confirmed associations to 47. Nat Genet. 2011;43(3):246-52. doi: 10.1038/ng.764.

4. Graham DB, Xavier RJ. From genetics of inflammatory bowel disease towards mechanistic insights. Trends Immunol. 2013;34(8):371-8. doi: 10.1016/j.it.2013.04.001.

5. Nutsch KM, Hsieh C-S. T cell tolerance and immunity to commensal bacteria. Curr Opin Immunol. 2012; 24(4):38591. doi: 10.1016/j.coi.2012.04.009

6. Neurath MF, Finotto S, Glimcher LH. The role of Th1/Th2 polarization in mucosal immunity. Nat Med. 2002;8(6):567-73.

7. Shale M, Ghosh S. Beyond TNF, Th1 and Th2 in inflammatory bowel disease. Gut. 2008;57(10):1349-51. doi: 10.1136/gut.2008.151563.

8. Brand S. Crohn's disease: Th1, Th17 or both? The change of a paradigm: new immunological and genetic insights implicate Th17 cells in the pathogenesis of Crohn's disease. Gut. 2009; 58(8):1152-67. doi: 10.1136/gut.2008.163667.

9. Di Sabatino A, Biancheri P, Rovedatti L, MacDonald TT, Corazza GR. New pathogenic paradigms in inflammatory bowel disease. Inflamm Bowel Dis. 2012;18(2):368-71. doi: 10.1002/ibd.21735.
10. Cunliffe RN, Mahida YR. Expression and regulation of antimicrobial peptides in the gastrointestinal tract. J Leukoc Biol. 2004;75(1):49-58.

11. Arijs I, De Hertogh G, Lemaire K, Quintens R, Van Lommel L, Van Steen K, et al. Mucosal gene expression of antimicrobial peptides in inflammatory bowel disease before and after first infliximab treatment. PLoS ONE. 2009;4(11): e7984. doi: 10.1371/journal.pone.0007984.

12. Peyrin-Biroulet L, Beisner J, Wang G, Nuding S, Oommen ST, Kelly D, et al. Peroxisome proliferator-activated receptor gamma activation is required for maintenance of innate antimicrobial immunity in the colon. Proc Natl Acad Sci USA. 2010;107(19):8772-7. doi: 10.1073/pnas.0905745107.

13. Noble CL, Abbas AR, Cornelius J, Lees CW, Ho GT, Toy $\mathrm{K}$, et al. Regional variation in gene expression in the healthy colon is dysregulated in ulcerative colitis. Gut. 2008;57(10):1398-405. doi: 10.1136/gut.2008.148395.

14. Granlund AV, Beisvag V, Torp SH, Flatberg A, Kleveland PM, Ostvik AE, et al. Activation of REG family proteins in colitis. Scand J Gastroenterol. 2011;46(11):1316-23. doi: 10.3109/00365521.2011.605463.

15. Simms LA, Doecke JD, Walsh MD, Huang N, Fowler EV, Radford-Smith GL. Reduced alpha-defensin expression is associated with inflammation and not NOD2 mutation status in ileal Crohn's disease. Gut. 2008; 57(7):903-10. doi: 10.1136/gut.2007.142588.

16. LaPointe LC, Dunne R, Brown GS, Worthley DL, Molloy PL, Wattchow D, et al. Map of differential transcript expression in the normal human large intestine. Physiol Genomics. 2008;33(1):50-64.

17. Wątroba M, Szukiewicz D. The role of sirtuins in aging and age-related diseases. Adv Med Sci. 2015;61(1):52-62. doi: 10.1016/j.advms.2015.09.003.

18. Terauchi K, Kobayashi H, Yatabe K, Yui N, Fujiya $\mathrm{H}$, Niki H, Musha H, Yudoh K. The NAD-Dependent Deacetylase Sirtuin-1 Regulates the Expression of Osteogenic Transcriptional Activator Runt-Related Transcription Factor 2 (Runx2) and Production of Matrix Metalloproteinase (MMP)-13 in Chondrocytes in Osteoarthritis. Int J Mol Sci. 2016;17(7). pii: E1019. doi: 10.3390/ijms17071019.

19. Brahmania M, Bernstein CN. Physician global assessments or blood tests do not predict mucosal healing in ulcerative colitis. Can J Gastroenterol Hepatol. 2014;28(6):325-9.

20. Isene R, Bernklev T, Høie O, Munkholm P, Tsianos $\mathrm{E}$, Stockbrügger $\mathrm{R}$ et al. Extraintestinal manifestations in Crohn's disease and ulcerative colitis: results from a prospective, population-based European inception cohort. Scand J Gastroenterol. 2015;50(3):300-5. doi: $10.3109 / 00365521.2014 .991752$

21. Dignass A, Eliakim R, Magro F, Maaser C, Chowers $\mathrm{Y}$, Geboes K, et al. [Second European evidence-based Consensus on the diagnosis and management of ulcerative colitis Part 1: Definitions and diagnosis (Spanish version)]. Rev Gastroenterol Mex. 2014;79(4):263-89. doi: 10.1016/j. rgmx.2014.10.001. [Article in Spanish]

22. Lennard-Jones JE, Shivananda S. Clinical uniformity of inflammatory bowel disease a presentation and during the first year of disease in the north and south of Europe. EC-IBD Study Group. Eur J Gastroenterol Hepatol. 1997;9(4):353-9. 23. Sands BE. From symptom to diagnosis: clinical distinctions among various forms of intestinal inflammation. Gastroenterology. 2004;126(6):1518-32.

24. Van Assche G, Dignass A, Panes J, Beaugerie L, 
Karagiannis J, Allez M, et al. The second European evidencebased Consensus on the diagnosis and management of Crohn's disease: Definitions and diagnosis. J Crohns Colitis. 2010;4(1):7-27. doi: 10.1016/j.crohns.2009.12.003.

25. Melmed GY, Elashoff R, Chen GC, Nastaskin I, Papadakis KA, Vasiliauskas EA, et al. Predicting a change in diagnosis from ulcerative colitis to Crohn's disease: a nested, casecontrol study. Clin Gastroenterol Hepatol. 2007; 5(5):602-8.

26. Ricanek P, Lunde LK, Frye SA, Støen M, Nygård S, Morth JP, et al. Reduced expression of aquaporins in human intestinal mucosa in early stage inflammatory bowel disease. Clin Exp Gastroenterol. 2015;8:49-67. doi: 10.2147/CEG. S70119.

27. Geboes K, De Hertogh G. Indeterminate colitis. Inflamm Bowel Dis, 2003;9(5):324-31.

28. Doss M, White MR, Tecle T, Hartshorn KL. Human defensins and LL-37 in mucosal immunity. $\mathrm{J}$ Leukoc Biol. 2010;87(1):79-92. doi: 10.1189/jlb.0609382.

29. Pütsep K, Carlsson G, Boman H, Andersson M. Deficiency of antibacterial peptides in patients with morbus Kostmann: an observation study. Lancet. 2002;360(9340):1144-9.

30. Iimura M, Gallo RL, Hase K, Miyamoto Y, Eckmann L, Kagnoff MF. Cathelicidin mediates innate intestinal defense against colonization with epithelial adherent bacterial pathogens. J Immunol. 2005;174(8):4901-7

31. Schauber J, Rieger D, Weiler F, Wehkamp J, Eck M, Fellermann K. et al. Heterogeneous expression of human cathelicidin hCAP18/LL-37 in inflammatory bowel diseases. Eur J Gastroenterol Hepatol. 2006;18(6):615-21.

32. Medina C, Radomski MW. Role of matrix metalloproteinases in intestinal inflammation. J Pharmacol Exp Ther. 2006;318(3):933-8

33. Wiesner J, Vilcinskas A. Antimicrobial peptides: the ancient arm of the human immune system. Virulence. 2010;1(5):440-64. doi: 10.4161/viru.1.5.12983.

34. Schmid M, Fellermann K, Fritz P, Wiedow O, Stange EF, Wehkamp J. Attenuated induction of epithelial and leukocyte serine antiproteases elafin and secretory leukocyte protease inhibitor in Crohn's disease. J Leukoc Biol. 2007;81(4):907-15. 35. Masuda K, Kamimura T, Watanabe K, Suga T, Kanesaki M, Takeuchi A, et al. Pharmacological activity of the C-terminal and N-terminal domains of secretory leukoprotease inhibitor in vitro. Br J Pharmacol. 1995;115(6):883-8.

36. Sallenave JM. The role of secretory leukocyte proteinase inhibitor and elafin (elastase-specific inhibitor/skin-derived antileukoprotease) as alarm antiproteinases in inflammatory lung disease. Respir Res. 2000;1(2):87-92.

37. Bergenfeldt $M$, Nyström $M$, Bohe $M$, Lindström $C$, Polling A, Ohlsson K. Localization of immunoreactive secretory leukocyte protease inhibitor (SLPI) in intestinal mucosa. J Gastroenterol. 1996;31(1):18-23.

38. Suzuki Y, Furukawa M, Abe J, Kashiwagi M, Hirose S. Localization of porcine trappin-2 (SKALP/elafin) in trachea and large intestine by in situ hybridization and immunohistochemistry. Histochem Cell Biol. 2000;114(1):15-20.

39. Okahara S, Arimura Y, Yabana T, Kobayashi K, Gotoh A, Motoya S, et al. Inflammatory gene signature in ulcerative colitis with cDNA macroarray analysis. Aliment Pharmacol Ther. 2005;21(9):1091-7.

40. Hiemstra PS, Maassen RJ, Stolk J, Heinzel-Wieland R, Steffens GJ, Dijkman JH. Antibacterial activity of antileukoprotease. Infect Immun, 1996;64(11):4520-4.

41. Shugars DC. Endogenous mucosal antiviral factors of the oral cavity. J Infect Dis. 1999;179 Suppl 3:S431-5.

42. Simpson AJ, Maxwell AI, Govan JR, Haslett C, Sallenave JM. Elafin (elastase-specific inhibitor) has anti-microbial activity against gram-positive and gram-negative respiratory pathogens. FEBS Lett. 1999;452(3):309-13.

43. Doumas S, Kolokotronis A, Stefanopoulos P. Antiinflammatory and antimicrobial roles of secretory leukocyte protease inhibitor. Infect Immun. 2005;73(3):1271-4.

44. Schmid M, Fellermann K, Fritz P, Wiedow O, Stange EF, Wehkamp J. Attenuated induction of epithelial and leukocyte serine antiproteases elafin and secretory leukocyte protease inhibitor in Crohn's disease. J Leukoc Biol. 2007;81(4):907-15. 45. Iwakura Y, Ishigame H, Saijo S, Nakae S. Functional specialization of interleukin-17 family members. Immunity. 2011;34(2):149-62. doi: 10.1016/j.immuni.2011.02.012.

46. Jiang W, Su J, Zhang X, Cheng X, Zhou J, Shi R, et al. Elevated levels of Th17 cells and Th17-related cytokines are associated with disease activity in patients with inflammatory bowel disease. Inflamm Res. 2014;63(11):943-50. doi: 10.1007/s00011-014-0768-7.

47. Ford J, Jiang M, Milner J. Cancer-specific functions of SIRT1 enable human epithelial cancer cell growth and survival. Cancer Res. 2005;65(22):10457-63.

48. Rajendrasozhan S, Yang SR, Kinnula VL, Rahman I. SIRT1, an antiinflammatory and antiaging protein, is decreased in lungs of patients with chronic obstructive pulmonary disease. Am J Respir Crit Care Med. 2008;177(8):861-70. doi: 10.1164/rccm.200708-1269OC.

49. Sharma M, Mohapatra J, Wagh A, Patel HM, Pandey D, Kadam S, et al. Involvement of TACE in colon inflammation: a novel mechanism of regulation via SIRT-1 activation. Cytokine. 2014;66(1):30-9. doi: 10.1016/j.cyto.2013.12.010.

50. Lukás K. [Idiopathic inflammatory bowel disease-prediction and treatment]. Cas Lek Cesk. 2011;150(6):315-20. [Article in Czech]. 